\title{
La subasta pública con único oferente: la naturaleza jurídica, sus fines e implicaciones*
}

\author{
The public auction with a single bidder: legal nature, purposes and implications \\ ○ leilão público com único licitante: a natureza jurídica, seus fins e suas implicações
}

DOI: https://doi.org/10.21803/pensam.v12i22.247

Fredy Andrés Pautt Barceló

https://orcid.org/0000-0002-6983-0972

Yasep Aristóteles Rentería Correa https://orcid.org/0000-0003-4166-8392

\section{¿Cómo citar este artículo?}

Pautt, F. \& Rentería, Y. (2019). La subasta pública con único oferente: la naturaleza jurídica, sus fines e implicaciones. Pensamiento Americano, $11(21)$, 57-70.

DOI: https://doi.org/10.21803/pensam.v12i22.247

\section{Resumen}

En este artículo de investigación tiene como finalidad establecer de qué manera la existencia de un único oferente constituye -o no- una vulneración al derecho constitucionalmente protegido de la libre competencia económica y bajo qué presupuestos se podría validar la subasta pública desde sus fines y su naturaleza jurídica, Lo anterior mediante un profundo análisis de las sentencias que han sido hito y han sido un punto de partida de despliegue jurisprudencial en las altas cortes, teniendo en cuenta los casos del tercer canal de televisión y de ISAGEN. En este escrito se abordará una defensa a la subasta pública con único oferente, dado que a nivel nacional se ha adoptado que esta solo es procedente cuando existe una pluralidad de interesados en aras del principio que permite una selección objetiva, transparencia y moralidad, en concordancia con el tipo de selección acordada. La subasta pública, su naturaleza jurídica y su finalidad en caso tal que se valide deben estar acorde no solo a la normatividad sino también a los principios generales del derecho administrativo y de la contratación.

Palabras Claves: Subasta pública, único oferente, libre competencia, naturaleza jurídica y fines de la subasta contratación estatal.

\begin{abstract}
This research article aims to establish how the existence of a single offeror constitutes - or not - a violation of the free competition economic rights and how the public auction could be valid from it's objectives and legal nature, the above, through an in-depth of the judgments analysis that were frames and has been a starting point of the law implementation cases in the superior courts, taking into consideration the cases of the third television channel and ISAGEN. This document will address a defense for the public auction with a single bidder, since at the national level it has been adopted that it's appropriate when there is a plurality of interested parties due to the principle that allows an objective selection, transparency and morality, in accordance with the modality of agreed selection. The legal nature and purpose of the public auction in case of validity must be consistent not only with the regulations, but also with the general principles of administrative law and contracting.
\end{abstract}

Keywords: Public auction, sole bidder, free competition, legal nature and state contract auction purposes.

\footnotetext{
*El presente trabajo fue desarrollado en virtud de un proyecto de investigación en la Maestría de Contratación Estatal en la Universidad de Medellín, en el transcurso del año 2017.
} 


\section{Resumen}

Este artigo de pesquisa tem por finalidade estabelecer de que maneira a existência de um único licitante constitui - ou não - uma vulneração ao direito constitucionalmente protegido da livre competência econômica e sob que pressuposto se podia validar o leilão público desde seus fins e sua natureza jurídica. Isto mediante um profundo análise das sentencias que foram marcos e ponto de partida jurisprudencial nas Altas Cortes (Instâncias), tendo em conta os casos do terceiro canal de televisão e de ISAGEN. Neste escrito se abordará uma defesa do leilão público com único licitante, dado que a nível nacional se adotou que este só é procedente quando existe uma pluralidade de interessados, por uma questão de princípios, que permitem uma seleção objetiva, transparência e moralidade, concorde com o tipo de seleção acordada. O leilão público, sua natureza jurídica e sua finalidade no caso tal que se valide devem estar acordes não somente à normatividade, mas também aos princípios gerais do direito administrativo e da contratação.

Palavras-chave: leilão público; único licitante, libre competência, natureza jurídica e fins do leilão de contrato estatal

\section{Perfil}

Fredy Andrés Pautt Barceló

Abogado de la Universidad del Norte. Candidato a Magister en Contratación Estatal en la Universidad de Medellín; Especialista en Responsabilidad y Seguros de la Universidad del Norte; Especialista en Contratación Estatal de Universidad de Medellín; Asesor Jurídico en entidades públicas y privadas. Fredypautt10@hotmail.com.

\section{Perfil}

Abogado de la Universidad de Medellín; Especialista Legislación Tributaria de la Universidad Autónoma Latinoamericana y Especialista Contratación Estatal de la Universidad de Medellín. Candidato a Magister en Contratación Estatal en la Universidad de Medellín. rcabogadosi@hotmail.com.
Abogado

Yasep Aristóteles Rentería

Correa

Abogado 


\section{Introducción}

El marco legal del sistema de compras del Estado Colombiano ha sido reformado de manera recurrente en pro de un aprovechamiento eficaz de los recursos públicos y a su vez hacerla más eficaz y eficiente con normas que dificultan la comisión de actos corruptos en los procesos de convocatoria pública. En la actualidad la contratación estatal está fundamentada en las siguientes normas: Ley 80 de 1993, Ley 1150 de 2007, Decreto 1082 de 2015, Ley 1474 de 2011, Decreto 777 de 1992, Ley 1437 de 2011, Decreto 92 de 2017, Código Civil y Código de Comercio; en la cual se define los principios básicos de la contratación administrativa y establece los diferentes tipos de modelos de selección y regla el procedimiento para ser ejecutados. Lo anterior es posible gracias a la consagración plasmada en la Constitución Política de 1991, que en el artículo 150 expresa: "Compete al Congreso expedir el estatuto general de contratación de la administración pública y en especial de la administración nacional" (Pérez, 2015, p.6).

La propiedad pública o la propiedad en sí, de todo el pueblo es una ficción jurídica. Los verdaderos propietarios de las cosas son quienes deciden qué hacer con ellas, trátese un individuo o de un pequeño grupo de ellos. Toda propiedad es privada. Eso lo saben bien los políticos estatistas que gustan arroparse en la bandera de la propiedad de todo el pueblo (Vélez, 2016, párr. 8).

La subasta la encontramos definida en la doctrina como una puja dinámica de precios, efectuada mediante la formulación de lances, para lograr una reducción sucesiva de precios durante un tiempo determinado. Dicha puja puede ser presencial o electrónica, de acuerdo con las reglas contenidas en los pliegos de condiciones. (Suárez Beltrán, 2014)
Partiendo de esta definición podemos detallar que se trata de una puja efectiva en la que un número plural de personas ofrecen de manera dinámica un precio el cual las contrapartes evalúan y realizan un mejoramiento de la oferta ofreciendo en puja un precio más alto, lo anterior regido y regulado por un pliego de condiciones que es ley para las partes. Detallando ya lo elementos constitutivos de la subasta podemos observar que el precio es el único factor de comparación entre las ofertas, puesto que al tener los bienes o servicios condiciones uniformes o estándar, las condiciones de los oferentes son revisadas como requisito habilitante, en el cual solo existe la opción de "pasar o no" a través del cumplimiento de los criterios establecidos en la ficha técnica en la que se indica las características que deben tener los bienes o servicios (Universidad de Medellín, 2014).

Por último, la finalidad de esta investigación es de qué manera la existencia de un único oferente constituye -o no- un quebrantamiento al derecho de la libre competencia y en qué forma se podría validar la subasta pública desde la naturaleza jurídica, sus fines e implicaciones como producto de un impacto jurídico en la contratación estatal. Esta es la pregunta problema que debemos desarrollar en este trabajo. Ahora, si en una subasta de un bien estatal, que en principio le "pertenece a todos" (del pueblo), muy posiblemente se deba requerir de la participación de varios oferentes, por cuestión de transparencia y moralidad. La subasta en la enajenación de un inmueble si bien puede realizarse con múltiples oferentes, también se puede realizar cuando exista ausencia de estos.

\section{Metodología}

El enfoque de este artículo es cualitativo debido a que este estudio está orientado a estructuras teóricas; por otro lado, como sus- 
tento, se usó información preferentemente información descriptiva y no cuantificada. La presente investigación se clasifica como jurídica por cuanto el objeto de la misma tiene asidero en las fuentes formales del Derecho y por tal razón se acudió a la revisión bibliográfica como técnica jurídica. Además, como se ha mencionado, con la consecución de los objetivos planteados se pretende la actualización del contenido básico o fundamental de la Ciencia Jurídica. Se trató de un estudio de carácter descriptivo-explicativo, porque buscó describir la evolución legal y jurisprudencial de la subasta con único oferente y su aplicación por los jueces en la jurisprudencia nacional, más exactamente por el Consejo de Estado y como se han ido aplicando la normatividad y la interpretación que se le ha dado a las mismas en casos análogos fallados por la jurisprudencia.

Este artículo utilizó una técnica documental que se basa en reunión, selección y análisis de datos, datos que son obtenidos para nuestro caso en particular de las jurisprudencias de las cortes enunciadas anteriormente.

Para alcanzar la consecución de los objetivos propuestos en el presente artículo daremos uso a las herramientas generadas por el Dr. Diego López Medina, para la construcción de líneas jurisprudenciales, la cual comprende un análisis del devenir jurisprudencial en un tema en específico, esto con el fin de determinar la trayectoria histórica y el estado actual del tema que se quiere investigar para lograr esto son puntos relevantes determinar cuáles son las sentencias que marcaron un punto consolidación - Sentencias Hito- de la temática investigada, llegamos a ellas a partir del análisis y organización de la producción jurisprudencial que se ha desarrollado, habiendo hecho lo anterior habrán sentencia donde encontraremos puntos de conexión -Sentencias Arquimedicas - que nos podrán llevar al origen de la decisión o de la institución que la Alta corte ha querido desarrollar. La anterior metodología para la construcción de la línea, podremos inferir la coherencia en la doctrina y por lo tanto su peso gravitacional como precedente (López Medina, 2006).

Las sentencias hito son aquellas que la alta corporación analiza consolidando los argumentos fácticos y jurídicos a la luz de las reglas y principios constitucionales, donde mediante una recopilación conceptual de su sentencia fundadora de línea; con esto da sustento y por ende razón de su decisión como punto de referencia máximo para una posición que posteriormente se desarrolle con otras sentencias que pueden mantenerse en su línea con respecto al punto de partida o cambiar su línea de argumentación. La sentencia arquimédica, son por decirlo así los puntos de conexión, que tiene el investigador para llegar a una primera decisión, este realiza una "ingeniería reversa" donde construye el desarrollo de la temática y le crea un camino para encontrar la sentencias hito y la fundadora de línea. Se obtendrá la información directamente de la jurisprudencia realizando líneas jurisprudenciales mediante ingeniería reversa de las mismas, auscultando desde las más recientes y buscando sus puntos de conexión hasta la más antigua y así poder identificar el desarrollo jurisprudencial En la sección tercera y sección cuarta del consejo de estado, además de fuentes primarias, como lo son doctrina, investigaciones, libros, revistas (López Medina, 2002).

Es menester dejar en claro que por ser un tema novedoso y por el poco, pero complejo -Caso venta de ISAGEN y Caso adjudicación 3er Canal de TV- desarrollo jurisprudencial; que la ocurrencia de estas condiciones de compraventa o adjudicación de bienes o servicios propios del estado, ha llevado en su tiempo a un debate nacional sobre la posibilidad o no de llevar a cabo dichas operaciones jurídicas que

Pensamiento Americano Vol. 12 - No. 23 • 2019 • Enero - Junio · Corporación Universitaria Americana • Barranquilla, Colombia • ISSN: $2027-2448$. 
encierran un deber de veeduría por el tema del optimo manejo de los recursos públicos a la ciudadanía en general.

\section{Resultados}

El enfoque de este trabajo ha sido el de realizar una investigación cualitativa de revisión legal y jurisprudencial respecto a la subasta pública con único oferente en Colombia. A partir de los objetivos planteados se describe explicativamente que las únicas sentencias que corroboran la tesis planteada hace viable la aplicación por parte de los jueces nacionales, exactamente las del Consejo de Estado (sección tercera y cuarta), tomando como ejemplo fallos análogos, bien, como la del Tribunal Administrativo de Cundinamarca (2016), se ha demostrado que si bien en todo proceso de contratación deben concurrir múltiples oferentes tal como sucede en una licitación pública o una selección abreviada, también puede resultar la situación en que una de estas modalidades pueda presentar un solo oferente, no solo porque la Ley lo permite para uno de los casos, sino también porque la norma no lo prohíbe para en el motivo en que existe la laguna.

La Ley 80 de 1993 y el Decreto 1082 de 2015 expresan sobre la aplicación de adjudicación/ enajenación de contratos/acciones por regla general su viabilidad, pero no como forma especial; como acontece en algunos casos como el de transferencia de activos por parte del Estado a un particular, pero este no puede ser óbice para orientarse bajo los principios de economía, democratización y continuidad del servicio derivado de las demandas sociales, políticas y económicas que se desprendan de la sociedad (globalización de mercados).

\section{Discusión}

De qué manera la existencia de un único oferente constituye una violación al derecho de la libre competencia económica y de qué forma se podría validar la subasta pública desde la naturaleza jurídica, sus fines e implicaciones como producto de un impacto jurídico en la contratación estatal. Esta es la pregunta problema que debemos desarrollar en este trabajo. Ahora, si en una subasta de un bien estatal, que en principio le "pertenece a todos" (del pueblo), muy posiblemente se deba requerir de la participación de varios oferentes, por cuestión de transparencia y moralidad. La subasta en la enajenación de un inmueble si bien puede realizarse con múltiples oferentes, también se puede realizar cuando exista ausencia de estos.

La propiedad pública o la propiedad en sí, de todo el pueblo es una ficción jurídica. Los verdaderos propietarios de las cosas son quienes deciden qué hacer con ellas, trátese un individuo o de un pequeño grupo de ellos. Toda propiedad es privada. Eso lo saben bien los políticos estatistas que gustan arroparse en la bandera de la propiedad de todo el pueblo. (Vélez, 2016, párr.8).

El diccionario jurídico define la subasta como una venta organizada de un producto basado en la competencia directa, y generalmente pública, es decir, a aquel comprador (postor) que pague la mayor cantidad de dinero o de bienes a cambio del producto. El bien subastado se adjudica al postor que más dinero haya ofrecido por él, aunque si la subasta es en sobre cerrado, el bien se adjudica a la mejor oferta sin posibilidad de mejorarla una vez conocida. El término subasta, sin el adjetivo "inversa", pero en esencia, solo modifica la dirección en que se realiza la puja por parte de los oferentes, pues ésta deja de ser de forma ascendente, para sustituirla por la descendente buscando así un mejor costo-beneficio para la entidad contratante, la cual tiene la potestad de escoger entre la modalidad de subasta inversa presencial o subasta inversa 
electrónica (Giraldo \& González, 1994, p.385, citado por Manjarrés \& Ortiz, 2012, p.6).

Sintetizando, pues, diré que la subasta inversa es una modalidad idónea, siempre y cuando la puja sea eficiente y justa por parte de los oferentes, esto quiere decir que los participantes deben garantizar la homologación, honestidad y transparencia en los bienes y servicios ofertados, es decir que las características de los bienes y servicios sean semejantes, verificables y comparables en igualdad de condiciones para todos los participantes, sólo así habrá una competencia sana, cuyo resultado será que el ganador sea el mejor al menor precio, sólo así lograremos que el Estado se vea beneficiado con la adjudicación de contratos (Navarro, 2015, p.19).

\section{De la validez y legalidad de la subasta pú- blica en los eventos que se presente un ofe- rente único.}

La Corte Constitucional, en pronunciamiento sobre los principios rectores de la contratación administrativa plasmada en la Ley 80 de 1993, de la siguiente forma:

El principio de la autonomía de voluntad, en virtud del cual la Administración pública está en capacidad de celebrar todos los contratos que resulten necesarios para satisfacer los intereses de la comunidad; el principio de la prevalencia del interés público, que le reconoce a la Administración una prerrogativa especial para ajustar el objeto del contrato a las necesidades variables de la comunidad; el principio de la reciprocidad de prestaciones, según el cual, lo importante y relevante en el régimen de contratación es la equivalencia real y objetiva entre los derechos y obligaciones que surgen de la relación contractual, y no la mera equivalencia formal y subjetiva con la que se llega a la simple satisfacción de los intereses individuales considerados por las partes cuando se formalizó el contrato; y, finalmente, el principio de la buena fe, que obliga a la Administración Pública y a los particulares contratistas, a tener en cuenta las exigencias éticas que emergen de la mutua confianza en el proceso de celebración, ejecución y liquidación de los contratos (Corte Const., Sentencia C-892, 2001).

En este mismo sentido, se ha señalado que las modalidades de selección conforme a los principios están diseñadas para garantizar la selección objetiva, tal como Boquera Oliver (1963) lo define:

Un conjunto de actos, pronunciamientos y decisiones que permiten a la administración, salvaguardando sus intereses económicos y el principio de igualdad de los administrados antes los beneficios y cargas públicas, elegir, de entre las personas que voluntariamente se ofrecen para ello, al sujeto más apto para contra$\operatorname{tar}($ p.12).

Para Matallana Camacho (2015) con la libertad de concurrencia se garantiza la participación del mayor número de oferentes, que se traduce en una mayor posibilidad de obtener la propuesta más favorable para los intereses de la entidad estatal; en esos términos se ha expresado el Consejo de Estado, quien ha establecido que las finalidades de la licitación pública son las de obtener, dentro de la gestión de los servicios a cargo del Estado, las condiciones más favorables y, a su vez, garantizar al ciudadano la igualdad de condiciones frente a la gestión administrativa (p.537).

Una vez garantizado esta libertad y los principios, de acuerdo al artículo 2.2.1.2.1.2.2., establecido en el (Decreto 1082, 2015), los pliegos de condiciones deben indicar: i) la fecha y hora de inicio de la subasta; ii) la periodicidad de los Lances; y iii) el Margen Mínimo para mejo- 
rar la oferta durante la subasta inversa. Si en el Proceso de Contratación se presenta un único oferente cuyos bienes o servicios cumplen con la ficha técnica y está habilitado, la Entidad Estatal puede adjudicarle el contrato al único oferente si el valor de la oferta es igual o inferior a la disponibilidad presupuestal para el contrato, caso en el cual no hay lugar a la subasta inversa (Pérez, 2015, p.15).

Dentro del pliego de condiciones estará indicado las pautas para la enajenación, adjudicación..., de los bienes, servicios, acciones..., en este caso Matallana Camacho (2015) expresa que la subasta inversa se presenta cuando las entidades a utilizar el mecanismo de esta conforman laboriosamente las ofertas en los procesos de licitación públicos. (p.627). Lo mismo indica para las reglas de subasta presencial y electrónica (p.644). Destaca el proceso de selección abreviada de enajenación de bienes del Estado, en el que expresa que pueden adelantar por procesos simplificados para garantizar la eficiencia de la gestión contractual (p. 667). Por tanto, en los estudios previos para la enajenación de bienes del estado deberán incluir las normas que adicionen sustituyan el avalúo del bien, el precio, y demás (682; Sánchez, 2007, p.25).

Por otra parte, la sentencia de Sala Plena del Consejo de Estado (2010) señaló que la concesión de frecuencias para utilizar el espectro electromagnético, aso del tercer canal de televisión, exige la concurrencia como mínimo de dos oferentes en el proceso licitatorio, que garantice al estado maximizar recursos por la utilización del bien y disponer de condiciones de calidad en la programación propuesta, y al no satisfacer estos fines se estaría violando la constitución y la ley. Por tanto, toda reproducción en la ejecución de la subasta debe estar sujeta a este pliego. El pliego es la ley de la parte en materia de contratación privada, es el procedimiento.
Por ende, al solo estar habilitado un único oferente en un proceso de subasta viola de manera clara y directa preceptos constitucionales y legales, puesto que se estaría favoreciendo las condiciones para la no pluralidad de oferentes y la concurrencia y competencia libre de los mismos a la puja para asegurar así una mejor ganancia en favor del estado y asegurar así los principios rectores de la contratación estatal como lo son la transparencia, la eficiencia y la selección objetiva. Aunque se crea que como sucedió en el tema del tercer canal de tv se tuvo en cuenta la pluralidad de oferentes, deberían contrastarse y aplicarse en el tema específico de ISAGEN, y no es cierto, son dos casos totalmente diferentes. Es de relevancia anotar que el Consejo de Estado parte del razonamiento usado y plasmado en el caso de tercer canal de tv no se expresa que se presente ausencia de ley, ni se señala nada acerca de la subasta con único oferente; de hecho, no es suficiente la invocación de los principios de moralidad, transparencia en esta. Por tanto, no es dable aplicar el fallo del tercer canal de televisión al caso ISAGEM por las razones antes expuestas.

\section{Del análisis de las fuentes del derecho co- lombiano y su aplicación al caso en con- creto}

La clave de esto está en la norma misma en el que indique si se necesita de un único oferente o de la pluralidad, en ausencia de este, por lo que su desarrollo estará presente en el pliego de condiciones. Por tanto, ante una contradicción del uno y la otra, prevalecerá la Ley, Decreto... por tanto, no hay ninguna norma en el ordenamiento jurídico colombiano que prohíba expresamente la realización de subastas con un oferente único (norma de prohibición). De no existir esa ley, aplica la Ley 80 de 1993 y el Decreto 1082 de 2015 lo que permite la adjudicación a un sólo oferente, que es la ley general; no habiendo ley especí- 
fica. En este caso los principios se deben utilizar como guía-orientador en ausencia total de norma, en línea del principio de economía. Por tanto, una sola oferta no impide que haya una selección objetiva y transparente.

Corolario de lo anterior podríamos decir de una vez que:

La posibilidad de adjudicar a un oferente único, no es insólito frente al derecho comparado. Esa posibilidad también se va en el Derecho Español (Ley 30, 2007, art. 135.1) y en el Derecho Argentino (Decreto 436, 2000, art.82), entre otros. En los anteriores ordenamientos jurídicos foráneos en cuestiones de telecomunicaciones existe también la misma disposición legal. También Así, por ejemplo, el (Decreto 741, 1993, art.53) consintió que en los procesos de selección para adjudicar la prestación del servicio de telefonía móvil celular fuere posible adjudicar a un único oferente. Por tanto, no se vulnera e I principio de selección objetiva ni un detrimento patrimonial por el hecho de no haber puja entre un numero plural de oferentes. La anterior posición fue tomada por los organismos de control como lo son la Procuraduría General de la Nación y la Contraloría General de la Republica en las gestiones precontractuales tendientes al instaurar la convocatoria pública para la adjudicar el tercer canal de televisión nacional (Ariza, 2010, párr.1).

El Consejo de Estado si recordamos nuevamente el asunto de la licitación del tercer canal de television, decidió que el tercer canal de televisión privado "no se puede adjudicar por subasta a un oferente único", lo que no se previó es que los fines y la naturaleza jurídica era distinta. Bien porque la norma misma lo exigía, no sucede frente a otros casos, donde ese vacío es nulo; por ejemplo, en el tercer canal de tv consideraron que en el proceso hubo una violación del Estatuto de las Telecomunicaciones (Ley 1341, 2009, art.72) que establece la pluralidad en las licitaciones referentes al espacio electromagnético y no fue cierto. En el caso de las licitaciones estatales se admite la adjudicación cuando hay un único oferente, pero en el caso de la subasta no es aplicable. No se puede decir que el Gobierno no tuvo el tiempo para ampliar el término y hacer la extensión a todos los oferentes; para así obtener una mayor competencia en el proceso; pero bien estos términos no pueden ser interminables.

En un Auto del Consejero Ponente Jorge Octavio Ramírez (2015) se concluye que el procedimiento más expedito y procedente para cesar los efectos de la regulación procedimental del procedimiento de subasta, se debió deprecar la nulidad del reglamente de enajenación y adjudicación de la segunda etapa, acto el cual no fue atacado en la demanda por tanto no puede ser objeto de la medida cautelar.

Nuevamente, la Sección Cuarta del Consejo de Estado negó declarar nulos los Decretos 1609 y 2316 del 2013 y 1512 del 2014, en el que se expresó que la autorización para vender ISAGEN vulneraba el patrimonio público, está no estando sustentada en estudios técnicos que la justificaran y que no era conveniente ni necesaria para financiar las vías 4G, como lo dijo el Gobierno Nacional.

Además, carecía de estudios previos que la justificaran, vulnerando así los principios de contratación, de economía, planeación y responsabilidad. La venta de una empresa del Estado debe estar fundamentada no solo en la Constitución sino también en la (Ley 226, 1995) además que la motivación que justifica la venta de un activo comercial del estado son cuestiones que por regla general no pueden ser objeto de un juicio de legalidad.

Pensamiento Americano Vol. 12 - No. 23 · 2019 • Enero - Junio • Corporación Universitaria Americana · Barranquilla, Colombia • ISSN: 2027-2448 · 
Para la Consejo de Estado (2015), los Decretos demandados para su nulidad se ajustaron a respetaron los principios de patrimonio público, continuidad del servicio preferencia y democratización. A su vez que el procedimiento y trámite para su expedición se ajustó a la Ley 226 de 1995.

Por un lado, notamos que quienes no estaban de acuerdo con la venta de ISAGEN los cuales en su defensa invocaban la Sentencia que el Consejo de Estado emitió el 15 de febrero de 2012, en la cual declaro la nulidad del proceso licitatorio y su adjudicación del tercer canal de televisión, en razón que si bien el pliego de condiciones definitivo autorizada a adjudicar a un proponente único habilitado, y el ordenamiento jurídico colombiano no sustenta dicha actuación con una norma de permiso que le dejara realizar la adjudicación pero tampoco que las prohibía, tal como hemos mencionado. Independientemente de los preceptos legales la Corte estimo que, al momento de no darse la puja por falta de pluralidad de oferentes, se estaría violando normas de carácter constitucional puesto que el artículo 209 estipula que:

La función administrativa está al servicio de los intereses generales y se desarrolla con fundamento en los principios de igualdad, moralidad, eficacia, economía, celeridad, imparcialidad y publicidad (...)

Entonces, mientras no exista norma que diga lo contrario y el acto este reservado en el pliego de condiciones, estudios previos..., y en él se plasme que, de igual manera, aunque hubiere un único habilitado se desarrollaría la subasta con un oferente único.

Entonces, mientras no exista norma que diga lo contrario y el acto este reservado en el pliego de condiciones, estudios previos..., pues se exigiría que haya puja o competencia, propias de las subastas así sea con un solo oferente

El profesor Mario Roberto Molano, expresa el compartimiento de comparte la teoría jurídica anteriormente señalado puesto que en su texto plasma que si la entidad estatal ha desplegado toda sus esfuerzos en pro de lograr la pluralidad oferente y fracasa por razones externas a la estructuración o causas no imputables a ella y esta desarrollo la convocatoria pública respetando la pluralidad de oferentes, la transparencia y la imparcialidad se podrá adjudicar el contrato al oferente único previamente habilitado. (Molano, 2009, p.307).

Deik (2014) expresa al respecto:

En virtud del (Decreto 1510, 2013, \#5 art 4) -hoy recogido en el Decreto Reglamentario 1082 de 2015- si en el proceso de contratación se presenta un único oferente cuyos bienes o servicios cumplen con la ficha técnica y se encuentra habilitado, la entidad estatal "puede" adjudicarle el contrato a dicho oferente siempre que el valor de la oferta sea igual o inferior a la disponibilidad presupuestal para el contrato, caso en el cual no se realizará la subasta inversa. En nuestro concepto, más que una potestad se trata de un deber, puesto que no habría razón para que la entidad se abstenga de adjudicarle el contrato a dicho oferente único en atención al principio de economía (p.234).

Evento en que se presente una sola oferta y siempre que cumpla con los requisitos habilitantes exigidos y satisfaga los requisitos de los pliegos de condiciones, la entidad puede adjudicar el contrato a la oferta única, salvo las disposiciones especiales para la subasta inversa, el concurso de méritos y las convocatorias limitadas a las Mypimes.

Remitiéndonos a la (Ley 226, 1995) misma, esta nos expresa, que, si es cierto el reglamen- 
to de enajenación contempla la referencia de que haya solo una oferta encomiable, no es menos cierto que no se puede interpretar que existiese solo la posibilidad en la ley de un único oferente especial, por tanto, no se expresa nada de la hipótesis de subasta de esta naturaleza, como sí lo hace la ley general de contratación, por tanto, se debe remitir a la ley general.

Si tenemos en cuenta el (Decreto 1082, 2015) -en relación con la Ley 80- no es posible aplicarla en los procedimientos de enajenación. Causando cambios en competencia en pro de la economía, casualmente cuando se trata de únicos oferentes; en sintonía de conseguir discusión por la puja de ofertas en pro de buscar mejores objetivos en beneficio no solo del Estado, sino también de la comunidad, esto, partiendo de un supuesto que no existe. La adjudicación de un contrato a un proponente único, se debe dar, siempre cumpliendo con los deberes y obligaciones que incluye el pliego de condiciones, a fin de tener conocimiento de los requisitos habilitantes, a lo que trata la subasta.

En similar sentido, la Sentencia definitiva del Consejo de Estado sobre el tercer canal (2014), del que se tardó en pronunciarse, indico unas fundamentaciones válidas para el único oferente, aunque se propugne la idea de tener una norma especial que genera una optimización de los recursos del Estado, tal como lo expreso la (Ley 1341, 2009, art. 72), al mostrar la pluralidad de oferentes en materia de concesión del espectro radioeléctrico, pero si se lee bien, deja la posibilidad de indicar de que haya uno solo proponente, eso sí, en caso que suceda, deberá garantizar según lo establecido en el pliego y demás documentos contractuales las condiciones claras y equitativas para la promoción interés general.

Si analizamos el régimen de venta para las empresas estatales, es una obligación legal someter la enajenación de dichas empresas por medio de un proceso de licitación pública -oferta pública de adquisición de acciones [OPA]- por medio de la bolsa de valores, con directrices justas que garanticen la concurrencia plural de oferentes en virtud del principio de libre competencia consagrados en el artículo 88 y 333 de la CN, al dar aplicación a lo anterior se actúa en consonancia de los principios rectores de la contratación estatal como lo son el principio de selección objetiva, transparencia y puesto que en el caso de la empresa ISAGEN, no se ha encontrado una norma que diga que no se puede hacer la subasta con un sólo oferente, aunque tampoco que lo mencione, existiendo hasta ahora una vaguedad de la norma. De no existir esa ley, se dice que se aplica la Ley 80 , como la Ley 226 de 1995, aunque se tomara la primera [...] (Daza, 2016, párr.3).

Al respecto el Articulo 20 de la Ley 226 de 1995, que la enajenación accionaria que se realice entre órganos estatales no se ajusta al procedimiento previsto en este Ley, sino que, para este efecto, se aplicarán únicamente las reglas de contratación administrativa vigentes. Así mismo, la venta de activos estatales distintos de acciones o bonos obligatoriamente convertibles en acciones sólo se sujetará a las reglas generales de contratación.

Para explicar este fenómeno y recogiendo lo dicho por Adam Smith, en primer lugar, para explicar cómo las dinámicas regulatorias del estado (Soberano) son incompatibles y excluyentes con los empresarios (Comerciantes), y por lo tanto la actividad comercial debe en mi sentir dejársela libremente a los particulares. Pero como en la contratación estatal uno de los principios rectores es el uso eficaz y eficiente de los recursos públicos la enajenación de sus activos comerciales -empresas- deben ser estudiadas y conceptuadas de manera 
juiciosa y detallada para determinar la conveniencia o no de la venta de las mismas.

El derecho administrativo es un ius commune, dentro de la unidad del derecho que constituye un ordenamiento completo, con principios e instituciones y categorías propias, con capacidad de autointegración para resolver en su ámbito el problema último de las lagunas legales que plantee la realidad y las eventuales contradicciones que su aplicación pueda provocar. Una muestra paradigmática la ofrece el régimen jurídico de los contratos de la administración (Meilán, 2011, p.17).

En segundo lugar, analizaremos que si en la búsqueda de la concurrencia y pluralidad de oferentes en un proceso de adjudicación viola de manera directa el principio de economía debido al detrimento y desgaste que genera la repetición de los procesos de selección de oferente por la falta de pluralidad de los mismos. Con respecto a los principios haciendo un énfasis en las posiciones señaladas y las tesis doctrinales y jurisprudenciales sobre el tema. A continuación, se realizará una descripción del estudio sobre las normas procedentes y los pronunciamientos de las altas cortes respecto de los principios y su aplicación (Manjarrés y Ortiz, 2012, p.5).

Para Miriam Cueto (2008), la finalidad de que las empresas privadas están sujetas a la legislación sobre contratación pública es el asegurar que cuando la ejecución de una obra de interés común se financia en más de un $50 \%$ por un poder adjudicador, por tanto, con dinero público, la asignación se realiza con unas mínimas garantías, con independencia de que el sujeto adjudicar el contrato sea público o privado (p.208). Y este puede ser producto de la globalización económica, expresándolo tal como lo entiende Mir Puigpelat, (2004), como actual coyuntura de creciente apertura y transnacionalización de los mer- cados, producción, materias primas, finanzas, capitales... de las actividades de empresas, a causa de los efectos de este del derecho y el derecho administrativo (p.27; Blanquer, 2013, p.255).

En una visión de la estructura de un sistema administrativo de defensa de la competencia en España nos expresa Guillén (2005) que las funciones y cometidos hacia donde encaminar sus actuaciones la administración pública varía con el tiempo conforme a las demandas sociales, políticas y económicas que se desprendan de la sociedad (p.27).

\section{Conclusión}

La naturaleza jurídica de la subasta inversa con único oferente está en la misma razón de la Ley 80 de 1993, Decreto 1082 de 2015 en concordancia con la Ley 226 de 1995 sobre enajenación y Decreto 734 de 2012 derogado orgánicamente, Lo anterior teniendo en cuenta los criterios para resolver antinomia, presente como laguna en el ordenamiento jurídico, como falta de plenitud tal como lo entiende Guastini (2011) y Comanducci (2011).

Los principios del derecho administrativo deben estar acorde con los principios generales del derecho también, como lo son la concurrencia, la transparencia, la responsabilidad, la buena fe, el debido proceso, la prevalencia del interés general, la economía, entre otros, en su máxima expresión, pero no este no puede ser óbice para impedir la adjudicación de un contrato, paralizando la actividad económica.

Por tanto, en el evento que en el marco de una convocatoria pública siendo está desarrollada bajo los principios rectores de la contratación pública, los preceptos reglamentarios o normas especiales y aplicando las disposiciones normativas de rango constitucional -Artículo 209- y lo analizado en el devenir de senten- 
cias para la estructuración de la línea jurisprudencial referenciada para el presente artículo en la cual contamos con dos sentencias las cuales son hito por su característica de ellas estar inmersa el punto arquimédica con el cual marcamos el inicio de la construcción de esta línea la cual en el caso colombiano solo se ha encontrado en dos casos de consonancia nacional los cuales son el Caso venta de ISAGEN y Caso adjudicación 3er Canal de TV. En estos casos el Consejo de estado trató de determinar si podemos o no si al momento de calificar a los oferentes en concurso y solo resultare un oferente único habilitado podemos adjudicar o no a este, puesto que como pudimos definir en el presente artículo podemos afirmar que por regla general si se podría realizar la adjudicación salvo que haya norma específica que lo prohíba, no sin antes otorgar la oportunidad de ampliar el término para que otros interesados presenten sus ofertas. Lo último un gran aporte plasmado en el Decreto 734 de 2012, subrogada por el Decreto 1082 de 2015.

\section{Referencias}

Ariza, W. (29 de junio de 2010). Si hay subasta de uno. Bogotá, Colombia: Portafolio. Recuperado de: http:// www.portafolio.co/opinion/weiner-ariza/hay-subasta-137530.

Blanquer, D. (2013). Los contratos del sector público. Valencia, España: Tirant lo blanch. Bobbio, N. Teoría general del derecho. Bogotá, Colombia: Temis.

Boquera Oliver, J. (1963). Los procedimientos de Selección de Contratistas. Madrid, España: Instituto de Estudios Políticos.

Comanducci, P. (2011). La interpretación jurídica. En Ferrer Beltrán, J. \& Battista Ratti, G. (Coord.), Realismo jurídico genovés. (pp. 52-70). Madrid, España: Marcial Pons.

Congreso de la República de Colombia (12 de julio de 2011). Por la cual se dictan normas orientadas a fortalecer los mecanismos de prevención, investigación y sanción de actos de corrupción y la efectividad del control de la gestión pública. [Ley 1474 de 2011]. DO: 48.128 .

Congreso de la República de Colombia (16 de julio de 2007). Por medio de la cual se introducen medidas para la eficiencia y la transparencia en la Ley 80 de 1993 y se dictan otras disposiciones generales sobre la contratación con Recursos Públicos. [Ley 1150 de 2007]. DO: 46.691.

Congreso de la República de Colombia (18 de enero de 2011). Por la cual se expide el Código de Procedimiento Administrativo y de lo Contencioso Administrativo. [Ley 1437 de 2011]. DO: 47.956.

Congreso de la República de Colombia (30 de julio de 2009). Por la cual se definen principios y conceptos sobre la sociedad de la información y la organización de las tecnologías de la información y las Comunicaciones -TIC-, se crea la Agencia Nacional de Espectro y se dictan otras disposiciones. [Ley 1341 de 2009]. DO: 47.426 . 
Congreso de la República de Colombia. (16 de junio 1971). Código de Comercio [C. Co]. [Decreto 140 de 1971]. DO: 33.339

Congreso de la República de Colombia. (20 de diciembre de 1995). Por la cual se desarrolla el artículo 60 de la Constitución Política en cuanto a la enajenación de la propiedad accionaria estatal, se toman medidas para su democratización y se dictan otras disposiciones. [Ley 226 de 1995]. DO: 42.159.

Congreso de la Republica de Colombia. (28 de octubre de 1993). Estatuto General de Contratación de la Administración Pública. [Ley 80 de 1993]. DO: 41.094

Congreso de la República de Colombia. (31 de mayo 1873). Código Civil [CC]. [Ley 57 de 1887]. DO: 2.867.

Consejo de Estado. Sala de Consulta y Servicio Civil. (25 de febrero de 2010). Sentencia. Exp. 11001-03-06-0002009-00049-00. [CP. William Zambrano].

Consejo de Estado. Sala de Consulta y Servicio Civil. (5 de octubre de 2009) Sentencia. Exp. 11001-03-06-0002009-00049-00. [CP. William Zambrano].

Consejo de Estado. Sala de lo Contencioso Administrativo. Sección tercera-subsección b (27 de marzo de 2014). Exp. 25000-23-15-000-2010-02404-01. [CP. Stella Díaz].

Consejo de Estado. Sala de lo Contencioso Administrativo. Sección Cuarta, (10 de septiembre de 2015). Exp. 1100103-26-000-2014-00054-00 [CP. Hugo Bastidas].

Consejo de Estado. Sala de lo Contencioso Administrativo. Sección Cuarta, (2 de diciembre de 2015), exp. 1100103-27-000-2015-00044-00(21848) [C.P Octavio Ramírez].

Consejo de Estado. Sala de lo Contencioso Administrativo. Sección Cuarta. (12 de enero de 2016). Rad. 11001-0327-000-2015-00044-00-21848. [CP. Jorge Ramirez].

Consejo de Estado. Sala de lo Contencioso Administrativo. Sección Cuarta. (3 de agosto de 2016). Rad.
11001032700020150004400-21848). [CP. Jorge Ramirez].

Consejo de Estado. Sección tercera (19 de julio de 2010). Sentencia. Exp. 11001-03-26- 000-2010-00036OO(38924). [CP. Mauricio Fajardo].

Corte Constitucional de Colombia. (22 de agosto de 2001). Sentencia C-892, 2001. MP: RODRIGO ESCOBAR GIL.

Cueto, M. (2008). Procedimiento administrativo, sujetos privados y funciones públicas. España: Thomson Civitas.

Daza, M. (18 de enero de 2016). 5 razones del porqué y del porqué no se deben vender ISAGEN. [Blog]. Recuperado de: http://derechopublicomd.blogspot.com. co/2016/01/5-razones-del-porque-y-del-porque- nose.html.

Deik, C. (2014). Guía de contratación estatal: Deber de planeación y modalidades de selección.

Guastini, R. (2011). Contribución a la teoría del ordenamiento jurídico. En Ferrer Beltrán, J. \& Battista Ratti, G. (Coord.), Realismo jurídico genovés. (pp. 81-116). Madrid, España: Marcial Pons.

Guillén, J. (2005). Libre competencia y Estado autonómico. España: Marcial Pons.

López, M. D. E. (2002). Manual de Interpretación Constitucional. Consejo Superior de la Judicatura. Escuela Judicial Rodrigo Lara Bonilla.

López, M. D. E. (2006). El derecho de los jueces. Bogotá, Colombia: Legis. $2^{\mathrm{a}} \mathrm{ed}$.

Manjarrés, D. A. y Ortiz, S. M. (2012). La concurrencia de proponentes en la subasta inversa. [Monografía]. Bogotá, Colombia: Universidad Militar Nueva Granada. Recuperado de: http://repository.unimilitar.edu.co/handle/10654/9228.

Matallana, E. (2015). Manual de contratación de la adminis- 
tración pública. Bogotá, Colombia: Universidad Externado de Colombia.

Meilán, J. L. (2011). Categorías jurídicas en el derecho administrativo. España: Iustel.

Mir, P. (2004). Globalización, Estado y Derecho. Las transformaciones recientes del Derecho Administrativo. España: Thomson Civitas.

Molano, M. R. (2009). La Nueva Estructura de los Procesos Selectivos en la Contratación Estatal. Bogotá, Colombia: Editorial Nueva Jurídica.

Navarro, C. E (2015). La selección de oferente mediante la modalidad de subasta inversa en la contratación estatal colombiana. Bogotá, Colombia: Universidad Militar Nueva Granada.

Pérez, D. A. (2015). La contratación pública a través de la subasta inversa un estudio de revisión en Colombia, Perú y Ecuador [Monografía]. Bogotá: Universidad Católica de Colombia. Recuperado de: http://repository.ucatolica.edu.co/bitstream/10983/8259/4/trabajo\%20de\%20grado.pdf

Presidente de la Nación Argentina (30 de mayo de 2000). Reglamento para la adquisición, enajenación y contratación de bienes y servicios del Estado Nacional. [Decreto 436 de 2000].

Presidente de la Republica de Colombia (13 de abril de 2012). Por el cual se reglamenta el Estatuto General de Contratación de la Administración Pública y se dictan otras disposiciones. [Decreto 734 de 2012]. DO: 48.400 .

Presidente de la Republica de Colombia (16 de mayo de 1992). Por el cual se reglamentan la celebración de los contratos a que refiere el inciso segundo del artículo 355 de la Constitución Política. [Decreto 777 de 1992]. DO: 40.451 .

Presidente de la Republica de Colombia (20 de abril de 1993). Por medio del cual se reglamenta la telefonía móvil celular. [Decreto 741 de 1993]. DO: 40.838.

Presidente de la Republica de Colombia (23 de enero de 2017). Por el cual se reglamenta la contratación con entidades privadas sin ánimo de lucro a la que hace referencia el inciso segundo del artículo 355 de la Constitución Política. [Decreto 92 de 2017]. DO: 50.125.

Presidente de la Republica de Colombia ( 26 de mayo 2015). Por medio del cual se expide el decreto único reglamentario del sector administrativo de planeación nacional. [Decreto 1082 de 2015]. DO: 49.523.

Rey de España (30 de octubre de 2007). Ley de contratos del sector Público. [Ley 30 de 2007]

Sánchez, A. F. (2007). Como violar las normas de contratación estatal. Bogotá, Colombia: Ediciones Doctrina y Ley.

Suárez Beltrán, G. (2014). Estudios de derecho contractual público. Pontificia Universidad Javeriana de Bogotá. Legis: Primera Edición.

Tribunal Administrativo de Cundinamarca. Sección Primera, Subsección A (25 de enero de 2016). Rad. 25000-2341-000-2016-00106-01. CP: Solarte Maya.

Universidad de Medellín. (2014). Modalidades de selección. Selección abreviada. [Notas de Clases] Facultad de Derecho - Especialización en Contratación Estatal virtual, Medellín, Colombia.

Vélez, L. G. (12 de enero de 2016). Una propuesta libertaria, igualitaria, popular y democrática sobre ISAGEN [Blog]. Recuperado de: http://luisguillermovelezalvarez.blogspot.com.co/2016/01/una-propuesta-libertaria-igualitaria.html

2018, Vol. 12(23) 57-70 @The Author(s) 2018 Reprints and permission: www.americana.edu.co

https://www.coruniamericana.edu.co/publicaciones/ojs/index.php/pensamientoamericano/index 